\title{
Heady days in Princeton
}

\author{
Pursuit of Genius: Flexner, Einstein, \\ and the Early Faculty at the Institute for \\ Advanced Study \\ by Steve Batterson \\ A. K. Peters: 2006.314 pp. $\$ 39$
}

\section{John Stachel}

Punching "advanced study" into Google's search engine brings up more than 2 million entries, but heading the list is the Institute for Advanced Study (IAS) in Princeton. Born of the union between private philanthropy and individual vision, the institute was a typically American marriage consciously modelled on the one that gave birth in 1876 to Johns Hopkins University, the first research university in the United States.

The IAS was itself the model for many other centres, including the Mexican Centro de Investigación y de Estudios Avanzados (CINVESTAV), set up 45 years ago, which was typical of the way research on a national scale is sponsored and financed by national governments. (I have spent time at both the IAS and CINVESTAV.) The United Nations University's Institute of Advanced Studies, set up just a decade ago, suggests a possible future pattern, with research being envisaged, controlled and conducted by international agencies on an international scale.

It is interesting to read in Pursuit of Genius by Steve Batterson how the IAS fared in the early days under the direction of its founding genius, Abraham Flexner. Flexner made his name with a report in 1910 on the quality of medical education in the United States. His brother Simon, an MD, had persuaded John D. Rockefeller to lethim run a medical institute on the Johns Hopkins model; it also employed Flexner for some time. Meanwhile, two wealthy Bamberger siblings, Louis and Caroline, sold their Newark department store just before the 1929 economic crash and wanted to found a medical school. They approached Flexner, but he convinced them to abandon the idea in favour of an institute of higher learning, a hybrid centre with Johns Hopkins' scope and the Rockefeller Institute's methods.

Flexner's first great success, chronicled in detail by Batterson, was the founding of the School of Mathematics, in which he had the unintended help of Adolf Hitler. Einstein had originally agreed to spend half his time at the new institute, but when the Nazis came to power in Germany in 1933, he realized he could not return to Berlin. He was joined by mathematicians Hermann Weyl (after much soul searching and a nervous breakdown) and Kurt Gödel (who see-sawed between Vienna and Princeton) at the new institute's first home in Fine Hall, the Princeton mathematics building.

There were other successes during the decade, such as the building of a separate campus for the institute and the founding of several

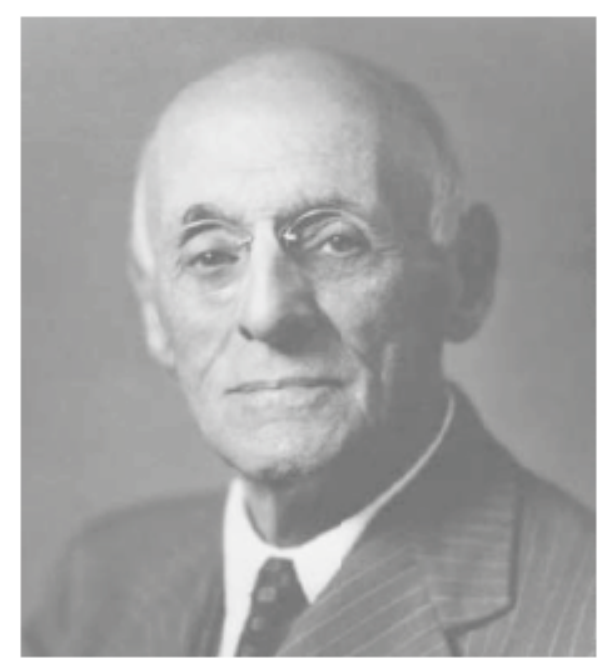

Abraham Flexner helped to establish the Institute for AdvancedStudy at Princeton.

other schools. But growing friction between Flexner's autocratic methods and the faculty's desire to participate in the institute's governance led to a struggle that culminated in Flexner's resignation in 1939. But the power struggle continued, as Batterson makes clear in a rather perfunctory final chapter giving a high-speed sketch of the intervening sixty-odd years of the institute's history.

The book is based primarily on a meticulous study of the institute's documentary records and the papers of some key players in its early history. Batterson tells a fascinating story, largely unvarnished, including such unsavoury details as the anti-Semitic atmosphere of Princeton at that time. The institute's patrons, its director and much of its initial faculty were Jewish, yet Flexner repeatedly refused to face up to anti-Semitism in the US educational system, let alone do anything to fight it.

More amusing are Batterson's detailed accounts of the turf war between Princeton University, particularly the mathematics department headed by Luther Eisenhart, and the institute's budding mathematics section, headed by Oswald Veblen.

The emphasis on documentary detail does not always generate a feeling for the setting in which these dramas took place. Einstein's letter to Belgium's Queen Elizabeth, written soon after his arrival, better conveys a sense of how incredibly provincial Princeton seemed to someone coming from Weimar Berlin: "Princeton is a wonderful little spot, a quaint and ceremonious little village of demigods on stilts... Here the people who compose what is called 'society' enjoy even less freedom than their counterparts in Europe. Yet, they seem unaware of this restriction since their way of life tends to inhibit personality development from childhood."

The use of Einstein's name in the title seems to be a hook to grab readers. Although he does play an important role in the story, it is no greater than that of many other early faculty, such as Veblen. The account of Einstein's private life is not always accurate and provides fewer new insights than the more fascinating account of Weyl's; those who want a more intimate picture should read Jamie Sayen's Einstein in America (Crown, 1985). Readers inclined to accept the myth that Einstein was completely isolated after his move to Princeton will be surprised at the large public role he played in shaping the fate of the institute, particularly in finally bringing down Flexner.

John Stachel is emeritus professor of physics and director of the Center for Einstein Studies, Boston University, Boston, Massachusetts 02215, USA.

\section{Display elements}

\section{The Periodic Table: Its Story And Its \\ Significance \\ Eric M. Scerri \\ Oxford University Press: 2006. 368 pp. £19.99, \$35}

\section{Bernadette Bensaude-Vincent}

The Periodic Table by Eric Scerri is the first major English-language monograph on the history of the periodic system since Jan van Spronsen's The Periodic System of Chemical Elements (Elsevier, 1969). Like van Spronsen, Scerri tries to understand the construction of the periodic table within the context of the history of matter theories. And like van Spronsen, he insists that it results from the collective work of many chemists. Chapter 3 , which begins with the early triads derived from Prout's hypothesis and presents six codiscoverers of the periodic system, provides a summary of van Spronsen's dassic study. However, his superficial overview of successive notions of elements mainly reinforces some popular clichés.

At this point, Scerri departs from van Spronsen. The historical sketch just provides the background for an exposition of his philosophical views on chemistry. Scerri, the editor of the journal Foundations of Chemistry, is interested above all in the question of whether chemistry can be reduced to quantum mechanics. He resolutely opposes Paul Dirac's 1929 claim that "the underlying physical laws necessary for the mathematical theory of a large part of physics and the whole of chemistry are completely known". The main purpose of his book is to 